\title{
Hippocampal Regulation of Postsynaptic Density Homer1 by Associative Learning
}

\author{
Nicholas E. Clifton, ${ }^{1}$ Darren Cameron, ${ }^{2}$ Simon Trent, ${ }^{1}$ Lucy H. Sykes, ${ }^{1}$ Kerrie L. Thomas, ${ }^{1,3}$ \\ and Jeremy Hall ${ }^{1,2}$ \\ ${ }^{1}$ Neuroscience and Mental Health Research Institute, Cardiff University, Cardiff CF24 4HQ, UK \\ ${ }^{2}$ MRC Centre for Neuropsychiatric Genetics and Genomics, Institute of Psychological Medicine and Clinical Neurosciences, \\ Cardiff University, Cardiff CF24 4HQ, UK \\ ${ }^{3}$ School of Biosciences, Cardiff University, Cardiff CF24 4HQ, UK \\ Correspondence should be addressed to Nicholas E. Clifton; cliftonne@cardiff.ac.uk
}

Received 14 July 2017; Revised 18 September 2017; Accepted 10 October 2017; Published 7 November 2017

Academic Editor: Anthony J. Baucum II

Copyright ( 2017 Nicholas E. Clifton et al. This is an open access article distributed under the Creative Commons Attribution License, which permits unrestricted use, distribution, and reproduction in any medium, provided the original work is properly cited.

\begin{abstract}
Genes involved in synaptic plasticity, particularly genes encoding postsynaptic density proteins, have been recurrently linked to psychiatric disorders including schizophrenia and autism. Postsynaptic density Homerl proteins contribute to synaptic plasticity through the competing actions of short and long isoforms. The activity-induced expression of short Homer 1 isoforms, Homerla and Ania-3, is thought to be related to processes of learning and memory. However, the precise regulation of Homerla and Ania-3 with different components of learning has not been investigated. Here, we used in situ hybridization to quantify short and long Homer1 expression in the hippocampus following consolidation, retrieval, and extinction of associative fear memory, using contextual fear conditioning in rats. Homer1a and Ania-3, but not long Homer1, were regulated by contextual fear learning or novelty detection, although their precise patterns of expression in hippocampal subregions were dependent on the isoform. We also show for the first time that the two short Homer1 isoforms are regulated after the retrieval and extinction of contextual fear memory, albeit with distinct temporal and spatial profiles. These findings support a role of activity-induced Homer1 isoforms in learning and memory processes in discrete hippocampal subregions and suggest that Homerla and Ania-3 may play separable roles in synaptic plasticity.
\end{abstract}

\section{Introduction}

The Homer1 gene codes for a family of postsynaptic density proteins with key roles in the control of synaptic plasticity [1-4] and learning and memory [5-7]. In humans and other mammals, several Homer1 isoforms exist, most of which are long and constitutively expressed whilst two shorter isoforms, Homerla and Ania-3, act as activity-induced immediate early genes $[8,9]$. Both long and short Homer1 proteins share the same $\mathrm{N}$-terminal binding domain and have common targets [10]. However, upon the recruitment of short Homers to the postsynaptic density, they disrupt the interactions between long Homers and their target proteins through dominant negative regulation $[11,12]$. Previous studies have shown that, by inhibiting the actions of long Homer isoforms, Homerla and Ania-3 regulate metabotropic glutamate receptor (mGluR) function [13-15] and calcium homeostasis [16-19].

Alterations of short Homer1 expression affect synaptic strength. Overexpression of Homerla in the hippocampus induces a glutamate-independent modulation of surface AMPA receptors [2, 20-22], reduced GluA2 subunit tyrosine phosphorylation [2], and blockade of long-term potentiation $[21,23]$. The ratio of short to long Homer1 in dendritic spines is a key mediator of AMPA currents [24, 25]. Further studies have also shown that hippocampal Homerla overexpression impairs spatial working and reference memory $[6,23]$, whilst knocking out Homer1 short forms cause 
deficits in fear conditioning $[7,26]$. However, the respective roles of Homerla and Ania-3 in learning and memory have not been distinguished.

In genetic studies of schizophrenia and other psychiatric disorders including autism, converging evidence points to postsynaptic density proteins in their aetiology [27-31], particularly those involved in the regulation of associative learning $[32,33]$. Postmortem analyses show that Homer1 protein levels are altered in patients with psychiatric disorders $[34,35]$. A recent study observed a decrease in long Homerl isoforms but increased short-form Homerla in postmortem hippocampal CA1 from patients with schizophrenia [36], suggesting that these patients had a higher ratio of short to long Homer1 proteins in this region. Furthermore, Homerla and Ania-3 are induced rapidly by psychoactive compounds [37], such as ketamine [38, 39] and cocaine [1, 40,41].

Homer1 activity has been shown to influence the functioning of other proteins and protein complexes linked to psychiatric disorders through genetic variants, such as FMRP $[28,42,43]$, CYFIP1 [27, 44, 45], Arc [27, 46], SHANK [10, $47,48]$, and the calcium channel $\mathrm{Ca}_{\mathrm{v}} 1.2[16,42]$. Genetic variants within the HOMER1 gene itself have been associated with schizophrenia in some studies $[49,50]$, and whilst more recent genome-wide association studies have not found a significant link between HOMER1 SNPs and schizophrenia, many of the interactors of Homer1 have been robustly associated with the disorder [42]. Furthermore, mutations in HOMER1 have also been associated with other psychiatric disorders including autism [51-53].

Whilst there has been substantial investigation of the induction of Homer1 isoforms following exposure to psychoactive compounds [38-41,54] and environmental stressors $[55,56]$ in rodents, fewer studies have focused on its expression after learning. Hernandez et al. demonstrated that the corticostriatal expression pattern of Homerla varies with successive trial of instrumental learning [57]. More recently, Mahan et al. reported that de novo Homerla expression occurs in the hippocampus and amygdala of mice following fear conditioning [7]. However, examination of Homer1 expression following constitutive components of associative learning has not yet been reported and no studies have examined the differential activation of the short Homer isoforms Homerla and Ania-3 during learning.

In order to explore the contribution from activityinduced Homer1 proteins to different components of associative fear learning, we quantified the respective expression patterns of Homerl isoforms after the consolidation, retrieval, and extinction of conditioned fear memories using a singletrial contextual fear conditioning paradigm $[58,59]$. In addition, to enable further interrogation of the precise role of these proteins in memory consolidation, we employed a protocol which separates the contextual fear conditioning paradigm into its constitutive parts. In the context preexposure facilitation effect (CPFE) protocol, the processes of learning about the context and associating the contextual memory with a footshock occur during separate, consecutive training events. Since context encoding is necessary for context conditioning $[60,61]$, only rats preexposed to the



Figure 1: Contextual fear conditioning induced robust postshock freezing. Rats were exposed to a novel context for $3 \mathrm{~min}$ and received a footshock after $2 \mathrm{~min}$. Data representative of all experimental groups culled $30 \mathrm{~min}, 2 \mathrm{~h}, 4 \mathrm{~h}$, and $24 \mathrm{~h}$ after conditioning for in situ hybridization ( $n=6$ per group). Data represented by mean \pm SEM percent freezing.

context that they are subsequently given an immediate shock in undergoing associative fear learning pertaining to that context. Thus, immediate early gene expression changes resulting from exposure to nonspecific aspects of fear conditioning versus the context-shock association can be quantified independently $[60,62]$.

\section{Materials and Methods}

2.1. Subjects. The subjects were 120 adult male Lister hooded rats (Charles River, UK) weighing 275-325 g. Rats were housed in pairs with food and water access ad libitum. The holding room was maintained at $21^{\circ} \mathrm{C}$ with a $12 \mathrm{~h}$ reversed light/dark cycle. Subjects were given at least 5 days to acclimatise to the holding room prior to testing. The handling of animals from each experimental group was ordered pseudorandomly. All procedures were conducted in accordance with the local Cardiff University Ethical Committee approval and the United Kingdom 1986 Animals (Scientific Procedures) Act.

2.2. Contextual Fear Conditioning. Rats underwent a contextual fear conditioning paradigm [63, 64]. In conditioning training trials, rats were individually exposed to a novel context (conditioning chamber; conditioned stimulus (CS)) for $3 \mathrm{~min}$. At $2 \mathrm{~min}$, rats received an unconditioned stimulus (US) consisting of a single scrambled footshock $(0.5 \mathrm{~mA}$, $2 \mathrm{sec}$ ). Freezing behaviour was quantified pre- and post-US as an index of conditioned fear. Rats were returned to their home cages immediately after conditioning and were killed by $\mathrm{CO}_{2}$ inhalation $30 \mathrm{~min}, 2 \mathrm{~h}, 4 \mathrm{~h}$, or $24 \mathrm{~h}$ after conditioning. Control subjects were naïve littermates killed at the same time of day as conditioned animals.

To compare the effects of the fear conditioning paradigm with solely the exposure to a novel context, rats were placed in a novel context for $3 \mathrm{~min}$ without the administration of a footshock and killed by $\mathrm{CO}_{2}$ inhalation $30 \mathrm{~min}$ afterwards. 
Homer1a
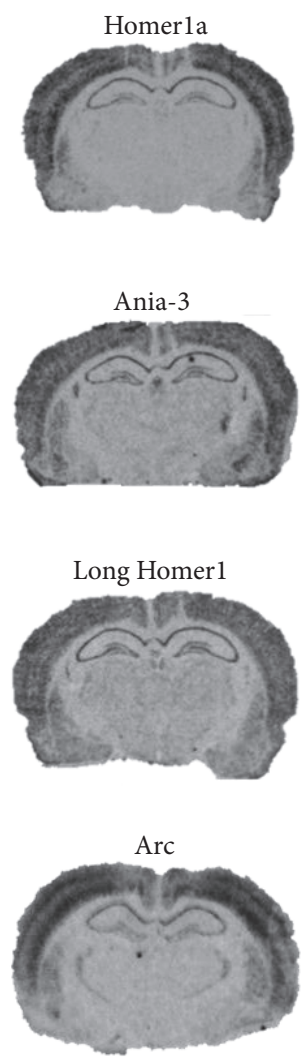

(a)



(b)

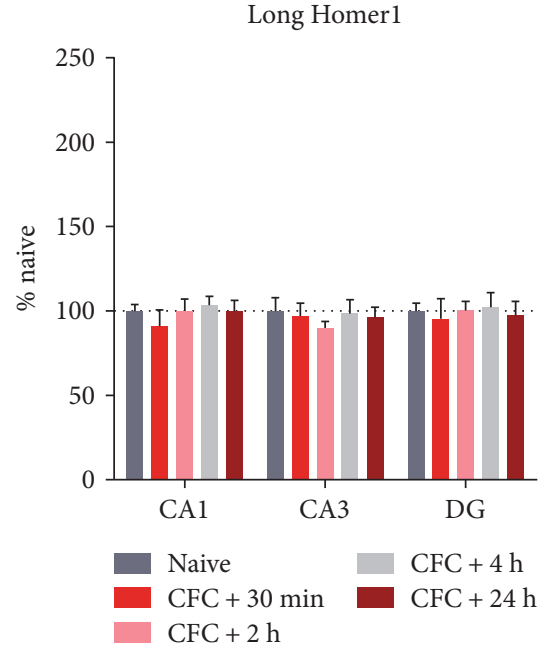

(d)



(c)



(e)

FIgURE 2: (a) Representative autoradiographs of coronal rat brain sections ( $-3.5 \mathrm{~mm}$ posterior to the bregma) hybridized with oligonucleotide probes targeting Homer1a, Ania-3, long Homer1, or Arc. (b-e) Hippocampal mRNA expression of (b) Homer1a, (c) Ania-3, (d) long Homer1, and (e) Arc following contextual fear conditioning (CFC). mRNA expression from the CA1, CA3, and dentate gyrus (DG) regions is represented by mean \pm SEM standardised optical density values, normalised to naïve controls (100\%). Brains were dissected $30 \mathrm{~min}, 2 \mathrm{~h}, 4 \mathrm{~h}$, or $24 \mathrm{~h}$ after conditioning. $n=6$ per group. Asterisks represent significance of the groups versus naïve control $\left({ }^{*} P<0.05\right.$, ${ }^{* *} P<0.01$, and $\left.{ }^{* * *} P<0.001\right)$.

These were compared to rats which had undergone a conditioning training trial and killed at the same time point. Freezing behaviour was quantified throughout the duration of context exposure.

Subjects from retrieval or extinction experimental groups underwent conditioning followed by a short or long recall trial, respectively. Recall trials took place $48 \mathrm{~h}$ after conditioning. Rats were reexposed to the conditioned context for $2 \mathrm{~min}$ (short recall; insufficient to produce extinction [64]) or $10 \mathrm{~min}$ (long recall, sufficient to produce extinction [64]) before being returned to home cages. Freezing behaviour during recall trials was quantified. Rats were killed $30 \mathrm{~min}$ or $2 \mathrm{~h}$ after recall trials. Control "no recall" subjects underwent a conditioning training trial and were killed $48 \mathrm{~h}$ afterwards.
Whole brains were immediately dissected and snap frozen on dry ice before storage at $-80^{\circ} \mathrm{C}$ until use in in situ hybridization.

2.3. Context Preexposure Facilitation Effect. In an immediate shock paradigm, rats were exposed to one of two different contexts, context A or context B, for $20 \mathrm{~min} /$ day for three consecutive days, to familiarise the animals to one context. On the fourth day, rats were placed into either the familiar context or the novel context. Subjects of the context preexposure facilitation effect (CPFE) group were placed into the familiar context and received an immediate footshock $(0.5 \mathrm{~mA}, 2 \mathrm{sec})$ before immediate removal. These were compared to two groups placed into the novel context for the same short duration: one group received an immediate 
Homerla

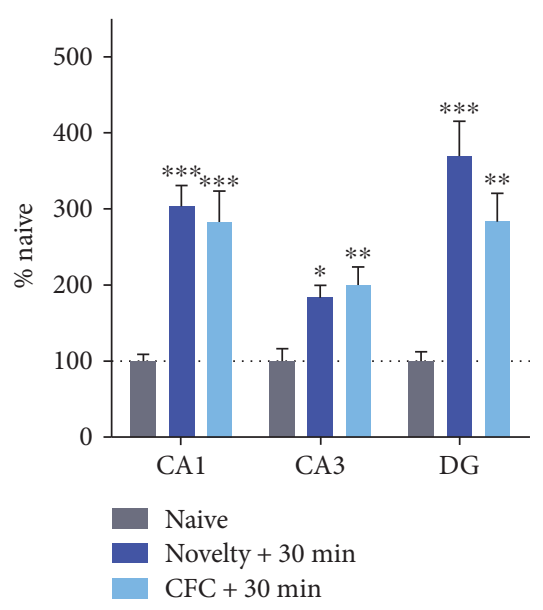

(a)

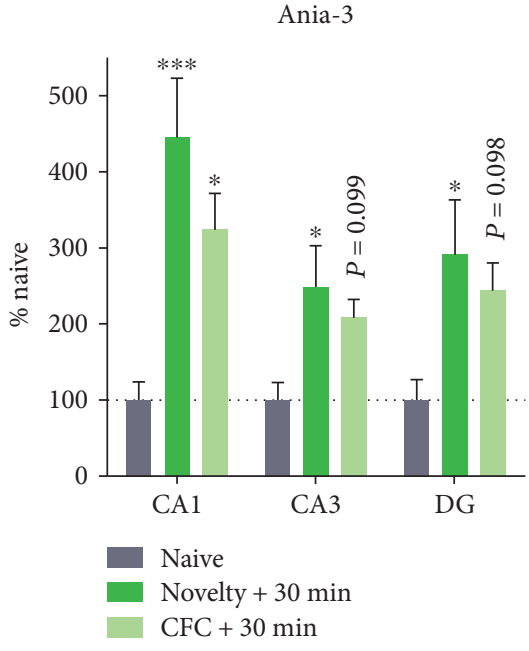

(b)



(c)

Figure 3: mRNA expression of (a) Homerla, (b) Ania-3, and (c) long Homer1 following exposure to a novel context or contextual fear conditioning (CFC). mRNA expression is represented by mean \pm SEM standardised optical density values, normalised to naïve controls $(100 \%)$. Brains were dissected $30 \mathrm{~min}$ after context exposure. $n=6$ per group. Asterisks represent significance of the groups versus naïve control $\left({ }^{*} P<0.05,{ }^{* *} P<0.01\right.$, and $\left.{ }^{* * *} P<0.001\right)$.

footshock (Novelty IS) and the other group did not (Brief Novelty). Rats were killed by $\mathrm{CO}_{2}$ inhalation 30 min after the final context exposure. A further group of naïve littermates was killed by $\mathrm{CO}_{2}$ inhalation at the same time of day. Whole brains were rapidly dissected and snap frozen on dry ice before storage at $-80^{\circ} \mathrm{C}$.

2.4. In Situ Hybridization. In situ hybridization is a method of localising and quantifying specific mRNA sequences in fixed tissue sections by hybridising with labelled strands of complementary nucleotide sequences. Coronal brain sections $(14 \mu \mathrm{m})$ containing dorsal regions of the hippocampus were cut, thaw mounted onto poly-L lysine-coated glass slides, and fixed in $4 \%$ paraformaldehyde prior to dehydration in ethanol and storage in $95 \%$ ethanol at $4^{\circ} \mathrm{C}$. Oligonucleotide probes were designed to target specific transcripts of the Homerl gene: Homerla, 5'-CATGATTGCTGAATTG AATGTGTACCTATGTGAAAATGGCAATGC-3'; Ania-3, 5'-GGTAGGGCGGAGGATTCATGACAGACAATACATG AACTTGGGCAG-3'. Long forms of Homer1 were targeted as a group with one oligonucleotide probe: $H o m e r 1 b / c / f / g$, 5'-CTCTGTCTTGTGGCTGTGCACCGCGTTTGCTTGAC TACTAACACA-3'. Arc expression was also assessed for comparison: Arc, 5'-AGCATCTCAGCTCGGCACTTACCA ATCTGCAGGATCACATTGGGT-3'. Oligonucleotide probes (Sigma-Aldrich) were $3^{\prime}$-end-labelled with $\left[\alpha-{ }^{35} \mathrm{~S}\right]$ dATP (PerkinElmer) then hybridized [65] to tissue sections matched for the hippocampal region across subjects. For each subject, two technical replicates were used. As a negative control, a third section was incubated with 100x excess of unlabelled probe. Autoradiographs were generated using radiographic film exposed to the sections for 5-10 days (probe dependent) and developed. Autoradiograph densitometry in three hippocampal subregions (Cornu Ammonis 1 (CA1), CA3, and dentate gyrus (DG)) was quantified as a measure of mRNA concentration.
2.5. Statistical Analysis. Percent freezing was compared within subjects (learning phase) and between groups (euthanasia time) using two-way repeated measures analysis of variance (ANOVA). Main effects of behavioural intervention on mRNA expression within each hippocampal subregion were determined using independent one-way ANOVA tests. Post hoc Dunnett's multiple comparison procedure was applied to data which surpassed a significance threshold (alpha $=0.05)$ in ANOVA, to determine specific group differences and directionality.

\section{Results}

3.1. Determining the Regulation of Homer1 Expression by Contextual Fear Memory Conditioning. To investigate memory consolidation-induced gene expression of Homerl, rats underwent a conditioning training trial. During contextual fear conditioning training, rats displayed robust postshock freezing, compared to baseline $(P<0.001$, two-way repeated measures ANOVA; Figure 1). Brains were extracted from separate groups $30 \mathrm{~min}, 2 \mathrm{~h}, 4 \mathrm{~h}$, and $24 \mathrm{~h}$ after conditioning for mRNA quantification, to observe the regulation of mRNA species over time.

Each Homer1 isoform was strongly expressed throughout all hippocampal areas observed, with the exception of weak Homerla expression in the dentate gyrus (Figure 2(a)). These expression patterns are consistent with those observed previously using similar methods [66].

Analysis of the expression of short Homer1 isoforms following contextual fear conditioning revealed a main effect on Homerla and Ania-3 in each hippocampal subregion (Homer1a: CA1 $\mathrm{F}_{(4,25)}=19.47, P<0.001$; CA3 $\mathrm{F}_{(4,25)}=7.13, P<0.001$; and $\mathrm{DG} \mathrm{F}_{(4,25)}=11.25, P<0.001$ and Ania-3: CA1 $\mathrm{F}_{(4,25)}=27.08, \quad P<0.001 ; \quad$ CA3 $\mathrm{F}_{(4,25)}=3.03, P<0.05$; and DG $\mathrm{F}_{(4,25)}=12.23, P<0.001$; one-way ANOVA, Figures 2(b) and 2(c)). The expression 


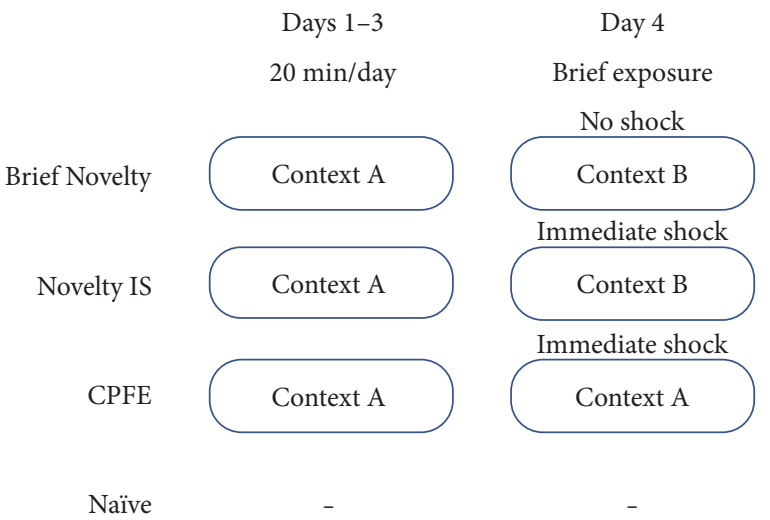

(a)

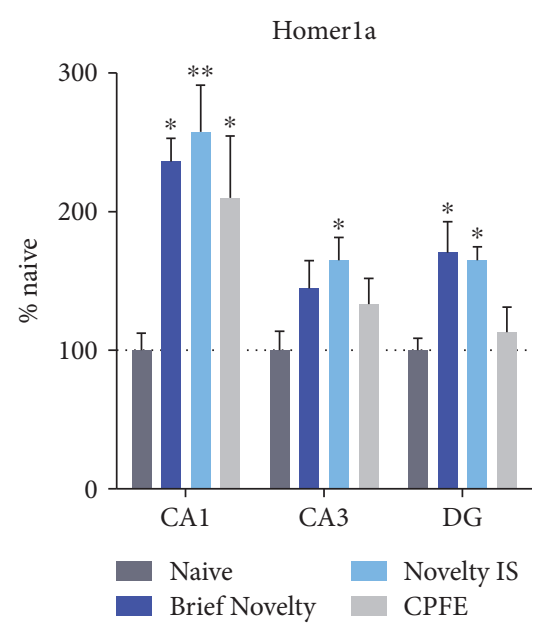

(b)

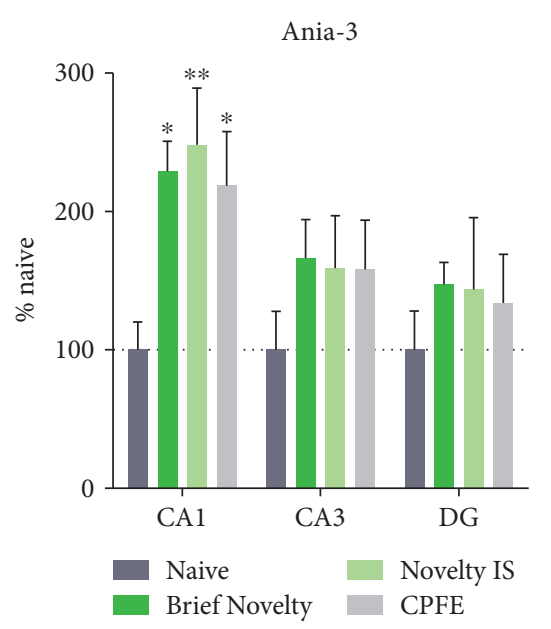

(c)

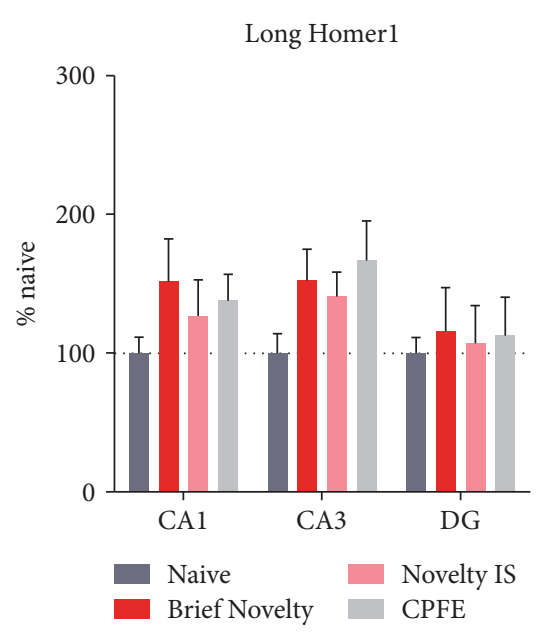

(d)

FIGURE 4: (a) Schematic displaying the context preexposure facilitation effect (CPFE) behavioural protocols. (b-d) Hippocampal mRNA expression of (b) Homer1a, (c) Ania-3, and (d) long Homer1 following a brief exposure to a novel context (Brief Novelty), brief novel context exposure with an immediate footshock (Novelty IS), and brief exposure to a familiar context with an immediate footshock (CPFE). mRNA expression is represented by mean \pm SEM standardised optical density values, normalised to naïve controls (100\%). Brains were dissected $30 \mathrm{~min}$ after the final context exposure. $n=6$ per group. Asterisks represent significance of the groups versus naïve control $\left({ }^{*} P<0.05,{ }^{* *} P<0.01\right)$.

of long Homer1 isoforms, as indicated by a pan-Homer1b/ $c / f / g$ oligonucleotide probe, was unchanged in all regions (CA1 $\mathrm{F}_{(4,25)}=0.47, P=0.75 ;$ CA3 $\mathrm{F}_{(4,25)}=0.31, P=0.87$; and $\mathrm{DG} \mathrm{F}_{(4,25)}=0.10, \quad P=0.98$; one-way ANOVA, Figure 2(d)). Arc expression, which has previously been shown to be coordinated with Homerla in hippocampal circuits [46, 67], was also affected by contextual fear conditioning in each subregion (CA1 $\mathrm{F}_{(4,25)}=8.69$, $P<0.001 ;$ CA3 $\mathrm{F}_{(4,25)}=9.81, P<0.001$; and DG $\mathrm{F}_{(4,25)}=6.93$, $P<0.001$; one-way ANOVA, Figure 2(e)). Post hoc Dunnett's tests indicated that Homerla expression was increased in the $\mathrm{CA} 1$ region at $30 \mathrm{~min}, 2 \mathrm{~h}$, and $4 \mathrm{~h}$ after conditioning and in the dentate gyrus at 30 min only. No changes in CA3 Homer1a expression were revealed in post hoc tests. In contrast, Ania-3 and $A r c$ expression was increased in all three hippocampal regions, yet solely at the $30 \mathrm{~min}$ time point (Figure 2).

3.2. The Regulation of Short Homer1 Isoforms by Novel Context Exposure. The previous experiments show that both Homerla and Ania-3 are induced in the hippocampus by contextual fear conditioning. Since this procedure involves the exposure of the animal to a novel context and past studies have shown Homerla to be upregulated by novelty alone [46], we also investigated the expression of Homerla and Ania-3 $30 \mathrm{~min}$ after novel context exposure compared to fear conditioning in separate cohorts. The expression of both short Homer 1 isoforms was modified by context exposure at this time point (Homer1a: CA1 $\mathrm{F}_{(2,15)}=15.42, P<0.001$; CA3 $\mathrm{F}_{(2,15)}=7.75, P<0.01$; and DG $\mathrm{F}_{(2,15)}=15.57, P<0.001$ and Ania-3: CA1 $\mathrm{F}_{(2,15)}=10.25, P<0.01 ; \mathrm{CA} 3 \mathrm{~F}_{(2,15)}=4.33$, $P<0.05$; and DG $F_{(2,15)}=4.13, P<0.05$; one-way ANOVA) but not the long Homer1 isoforms (CA1 $\mathrm{F}_{(2,15)}=0.83$, $P=0.46 ;$ CA3 $\mathrm{F}_{(2,15)}=0.49, P=0.62 ;$ and DG $\mathrm{F}_{(2,15)}=1.55$, $P=0.24$; one-way ANOVA, Figure 3 ). Post hoc Dunnett's tests were used to determine whether novel context exposure alone is sufficient to induce expression of the short Homer1 isoforms. Similarly to that seen previously, Homerla and Ania-3 appeared to be induced at $30 \mathrm{~min}$ by contextual fear conditioning in each hippocampal subregion, although there was only a trend $(P<0.1)$ to an 


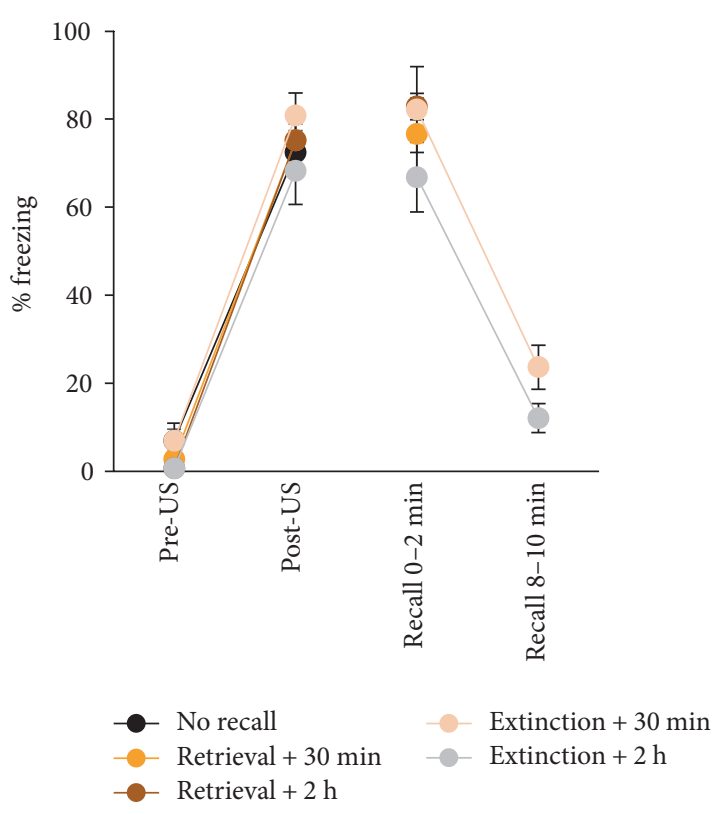

FIGURE 5: In the retrieval and extinction of contextual fear memory, rats displayed robust conditioned freezing and an extinguished response after long recall $(10 \mathrm{~min})$. Retrieval and extinction training took place $48 \mathrm{~h}$ after conditioning. Control "no recall" animals were conditioned and culled $48 \mathrm{~h}$ afterwards. Rats were culled $30 \mathrm{~min}$ or $2 \mathrm{~h}$ after retrieval and extinction for in situ hybridization. $n=6$ (30 $\mathrm{min}), n=12(2 \mathrm{~h})$, or $n=18$ (no recall) per group. Data represented by mean \pm SEM percent freezing.

increase in Ania-3 expression in CA3 and the dentate gyrus in this experiment. Novel context exposure significantly increased Homerla and Ania-3 expression in all regions. In all regions, there was no difference between the effects of conditioning or novel context exposure on the expression of Homerla. There was no change in the expression of Long Homer1 with novelty or CFC training in any hippocampal subfield (Figure 3).

3.3. The Regulation of Homer1 Expression Using the Context Preexposure Facilitation Effect (CPFE) Behavioural Model of Contextual Fear Conditioning. To further examine whether Homerla or Ania-3 are specifically induced by associative events (CS-US and context memory formation) or by the processes associated with the standard contextual fear conditioning paradigm such as novel stimulus presentation, we used a context preexposure facilitation effect (CPFE) procedure to further dissect the regulation of short Homer1 isoforms by associative fear learning. Training was split into three components: brief exposure (14-20 s) to a novel context with no presentation of the US (Brief Novelty); immediate footshock given upon exposure to a novel context (Novelty IS); and brief exposure to a familiar context with an immediate footshock (CPFE). Only the CPFE procedure is sufficient to generate an associative context-footshock fear memory [60-62]. Since we anticipated the time course of any induction in short Homerl gene expression to be similar to that observed following contextual fear conditioning previously, brains were only extracted $30 \mathrm{~min}$ after each behavioural intervention. There was a main effect of the group on Homerla and Ania-3 expression within the CA1 region of the hippocampus (Homerla: $\mathrm{F}_{(3,20)}=5.53$, $P<0.01$; and Ania-3: $\mathrm{F}_{(3,20)}=4.60, \quad P<0.05$; one-way ANOVA, Figures 4(b) and 4(c)). Homerla expression was also modified in the dentate gyrus $\left(\mathrm{F}_{(3,20)}=5.19, P<0.01\right)$, but was not significantly modified in CA3 $\left(\mathrm{F}_{(3,20)}=2.47\right.$, $P=0.092)$. Ania-3 expression was unchanged in CA3 $\left(\mathrm{F}_{(3,20)}=0.89, P=0.46\right)$ and DG $\left(\mathrm{F}_{(3,20)}=0.38, P=0.77\right)$. Post hoc Dunnett's tests on data from CA1 revealed that, compared to naivve controls, the expression of both Homerla and Ania-3 was increased in the CA1 region following each stimulus, irrespective of context-footshock pairing, implying that the induction of short Homerl isoforms did not depend on associative learning per se. There was a significant increase in the expression of Homerla in CA3 and the dentate gyrus in the Novelty IS group but not the CPFE group. Thus, there is a lack of correlation in the regulation of Homerla with associative CS-US learning in these two hippocampal subregions. In contrast, there were no significant changes in the expression of Ania-3 in either the CA3 or dentate gyrus with behavioural training. Therefore, there is dissociation between the transcriptional regulation of Homerla and Ania-3 expression with associative learning in the hippocampal CA3 and dentate gyrus.

Consistent with expression in the standard contextual fear conditioning protocol, the levels of Long Homer1 mRNA remained unchanged in all groups $\left(\mathrm{CA} 1 \mathrm{~F}_{(3,20)}=0.88\right.$, $P=0.47 ; \quad$ CA $3 \quad \mathrm{~F}_{(3,20)}=1.79, P=0.18$; and $\mathrm{DG} \mathrm{F}_{(3,20)}=$ $0.072, P=0.97$; one-way ANOVA, Figure $4(\mathrm{~d})$ ).

3.4. Expression of Short and Long Homer1 Isoforms following Contextual Fear Memory Retrieval and Extinction. In order to investigate whether short Homer1 isoforms are induced in the hippocampus by other associative learning processes, gene expression was quantified after the retrieval and extinction of contextual fear. All groups trained using the standard fear conditioning protocol displayed robust postshock freezing $\left(\mathrm{F}_{(1,31)}=492.9, P<0.001\right.$, two-way repeated measures ANOVA) and extinction training induced a within-trial reduction of freezing $\left(\mathrm{F}_{(1,10)}=115.1, P<0.001\right.$, two-way repeated measures ANOVA; Figure 5). Reexposure to the context for $2 \mathrm{~min}$ (retrieval), which is not sufficient to induce extinction [64], modified the expression of Homerla (CA1 $\mathrm{F}_{(2,33)}=28.78, P<0.001 ; \mathrm{CA} \mathrm{F}_{(2,33)}=4.98, P<0.05$; and DG $\mathrm{F}_{(2,33)}=5.61, P<0.01$; one-way ANOVA) and Ania-3 (CA1 $\mathrm{F}_{(2,33)}=11.64, P<0.001 ; \mathrm{CA} 3 \mathrm{~F}_{(2,33)}=9.04, P<0.001$; and DG $\mathrm{F}_{(2,33)}=5.08, P<0.05$; one-way ANOVA) compared to "no recall" control subjects (Figure 6). A 10 min recall trial (extinction) also affected the expression of both short Homerl isoforms across hippocampal subregions (Homerla: CA1 $\mathrm{F}_{(2,33)}=38.83, P<0.001 ;$ CA3 $\mathrm{F}_{(2,33)}=13.82, P<0.001$; and DG $\quad \mathrm{F}_{(2,33)}=4.47, \quad P<0.05$ and Ania-3: CA1 $\mathrm{F}_{(2,33)}=24.00, \stackrel{P}{<} 0.001 ; \mathrm{CA} 3 \mathrm{~F}_{(2,33)}=5.91, P<0.01$; and DG $\mathrm{F}_{(2,33)}=4.70, P<0.05$; one-way ANOVA). A significant retrieval-induced upregulation of Homerla occurred at $30 \mathrm{~min}$ and $2 \mathrm{~h}$ in CA 1 and CA3 and at $2 \mathrm{~h}$ only in the dentate gyrus. Ania-3 expression was upregulated at $30 \mathrm{~min}$, but not $2 \mathrm{~h}$, in all three hippocampal regions. The hippocampal expression pattern of each short Homer1 


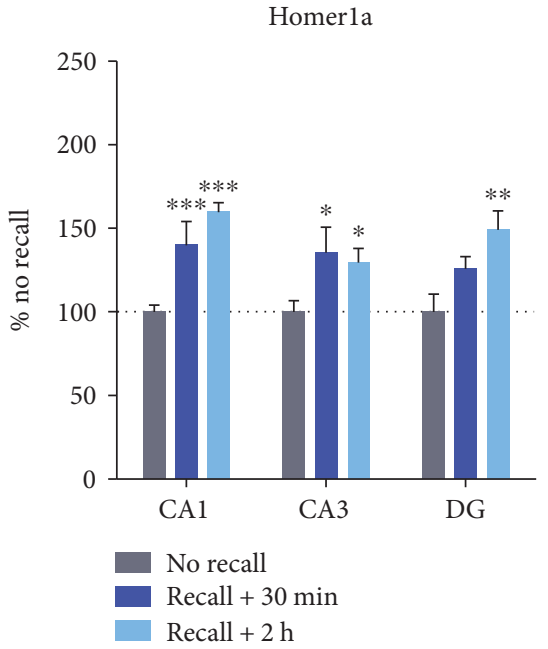

(a)

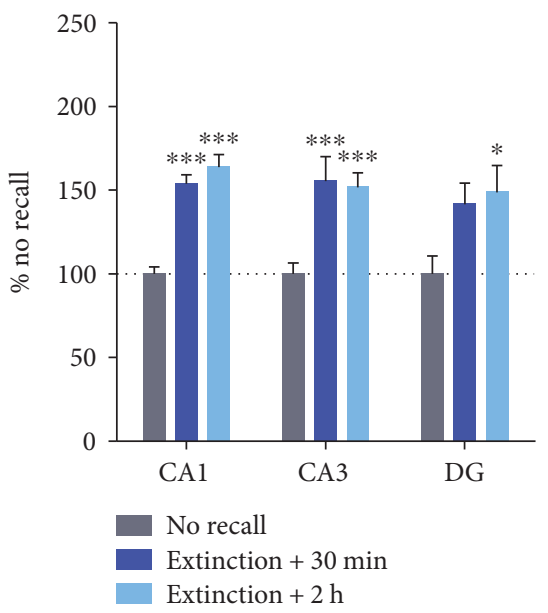

(d)

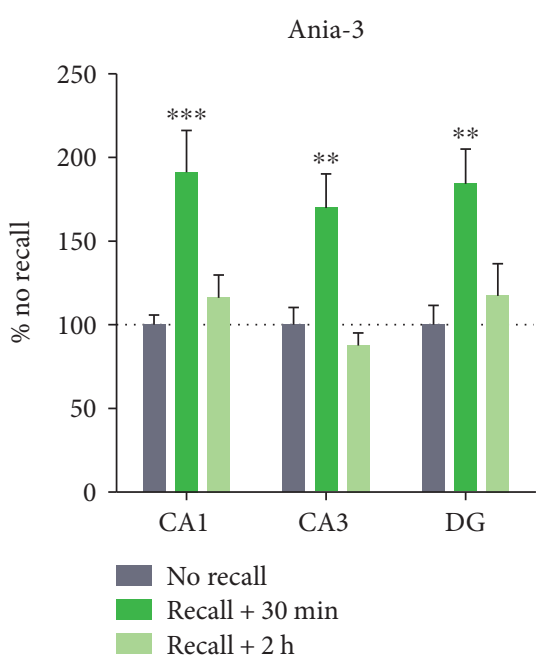

(b)

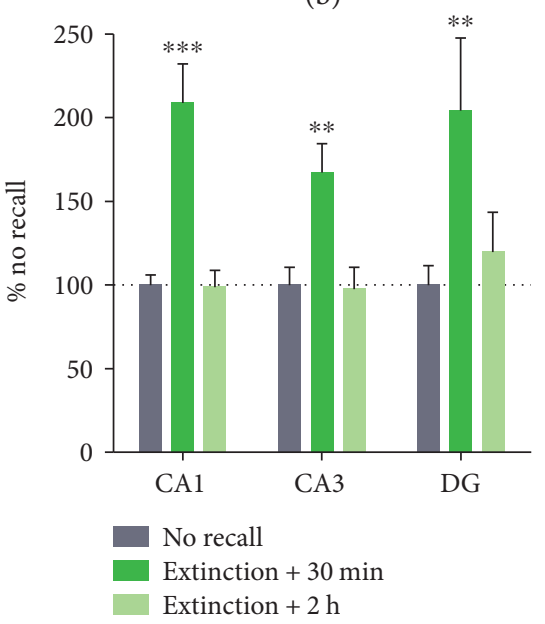

(e)

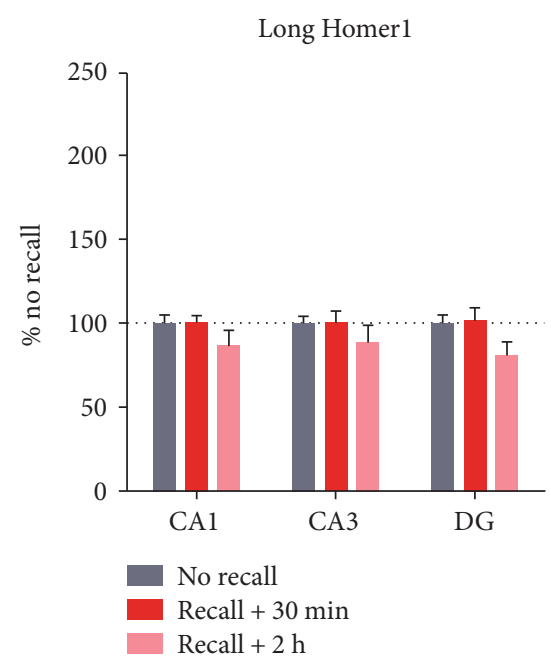

(c)

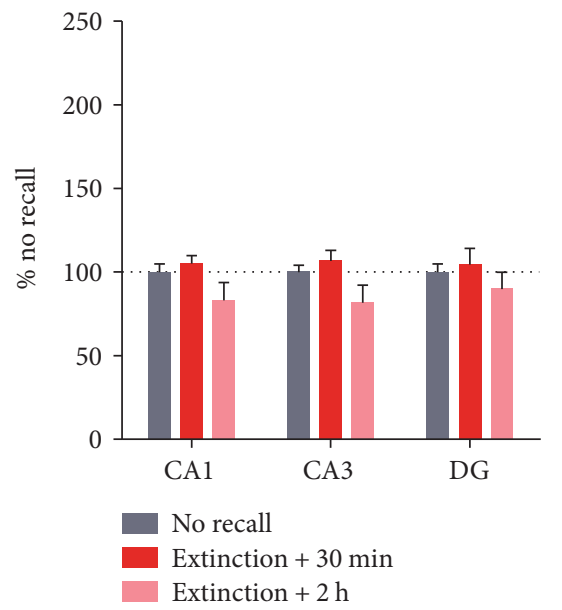

(f)

FIgURE 6: mRNA expression of Homerla, Ania-3, and long Homer1 in the hippocampus following the recall (a-c) or extinction (d-f) of contextual fear memory. mRNA expression is represented by mean \pm SEM standardised optical density values, normalised to no recall controls (100\%). Brains were taken $30 \mathrm{~min}$ or $2 \mathrm{~h}$ after reexposure. $n=6(30 \mathrm{~min}), n=12(2 \mathrm{~h})$, or $n=18$ (no recall) per group. Asterisks represent significance of the groups versus no recall control $\left({ }^{*} P<0.05,{ }^{* *} P<0.01\right.$, and $\left.{ }^{* * *} P<0.001\right)$.

isoform following extinction learning mirrored that following retrieval. Long Homer1 expression was unchanged by context reexposure in any of the hippocampal subregions observed (retrieval: CA1 $\mathrm{F}_{(2,21)}=1.40, \quad P=0.27$; CA3 $\mathrm{F}_{(2,21)}=0.91, P=0.42$; and $\mathrm{DG} \mathrm{F}_{(2,21)}=2.60, P=0.098$ and extinction: CA1 $\mathrm{F}_{(2,21)}=2.42, P=0.11$; CA3 $\mathrm{F}_{(2,21)}=3.22$, $P=0.060$; and DG $F_{(2,21)}=0.79, P=0.47$; one-way ANOVA).

\section{Discussion}

The present findings indicate that the expression of short Homer1 isoforms in the hippocampus is correlated with experiencing a salient context, which may contribute to the formation or maintenance of Pavlovian associations. Within this, the relative expression of Homerla and Ania-3 in different subregions of the hippocampus depended on the type of memory processing involved. Crucially, in some instances, the region-specific regulation of Homerla differed to that of Ania-3. In addition, the temporal profiles of Homerla and induction differed, with Ania-3 expression having a more curtailed profile. Long forms of Homer1, which were targeted as a group with one oligonucleotide probe, were not regulated by contextual fear conditioning, retrieval, or extinction or stimulus-driven experience in any hippocampal subregion or time point measured, consistent with its previously reported constitutive expression [8].

Homerla functions to potentiate synaptic transmission [22] and is required for the formation of fear memory [26]. The induction of short Homer1 isoforms in the CA1 is consistent with its role as a key region for the consolidation of contextual fear (CS-US) memory [68, 69]. Moreover, the hippocampus plays an important role in novelty detection [70-73]. Our data show that the expression of Homerla and Ania-3 in CA1 is also driven by novelty. The direct monosynaptic pathway from the entorhinal cortex conveys inputs from sensory systems to CA1 and to serve novelty detection [74]. As such, the regulation of short Homer1 isoforms may 
correlate with the contribution of novelty to the comparator function of CA1 and the encoding of memory [75].

The regulation of Homerla and Ania-3 in the CA3 and dentate gyrus after contextual fear conditioning and novelty exposure is more likely to be related to the Pavlovian associative events of contextual memory formation. The formation of conjunctive spatial or contextual representations is necessary for the formation of an association between a stimulus and a context (CS-US association) [76-81]. However, the absence of transcriptional activation in the CPFE group negates regulation in these regions correlated with CS-US formation. The increases in both Homer $1 a$ and Ania-3 expression in the dorsal CA3 and dentate gyrus are thus consistent with the role of these hippocampal subregions in the formation of contextual representation $[82,83]$. The pattern of transcriptional induction in the Novelty IS and Brief Novelty experimental groups, characterised by very short stimulus presentations, suggests that specific processes underlying arousal or attentional processes accompanying aversive footshock US and novel CS detection additionally regulate the expression of Homerla, but not Ania-3, in CA3 and the dentate gyrus. However, the observation of short Homer1 expression at additional time points may reveal a different pattern of induction. The possibility that Ania-3 may have a more restrictive role in the formation of contextual memory also demands further investigation.

The regulation of Homer $1 a$ and Ania-3 expression after contextual fear conditioning exhibited striking temporal differences. This was reflected in the duration for which the elevated expression level was detectable. Regulated Ania-3 expression was considerably more transient than Homerla in all hippocampal subregions. This observation, which is previously unreported, implies that these two activityinduced isoforms are regulated through different transcriptional and/or posttranscriptional mechanisms. It is possible that this discrepancy occurs due to differences in metabolic processing, yet may also have implications for the function of the translated proteins. Coincident regulation of Homer1a and $A r c$ in the hippocampus has been previously reported [46]. Whilst we show similar coincidental regional induction of Homerla and Arc with contextual fear conditioning, in terms of a temporal profile, the expression of Ania-3 more closely parallels the expression of Arc. Based on the current observations, it may be hypothesised that whilst these synaptic proteins may function in concert in the structural and synaptic modifications supporting memory formation, there is a closer association of Ania-3 and Arc-mediated processes.

We observed an increase in the expression of both Homer $1 a$ and Ania-3 in all three hippocampal subfields after conditioned context cued recall, whether the recall period was short $(2 \mathrm{~min})$ or long $(10 \mathrm{~min})$. These changes reflect the coordinated activity of the hippocampal subregions in the retrieval of contextual fear memory [84, 85]. Similar increases have been observed for other immediate early genes including Arc [86-88]. The transcriptional activation of the short Homer1 isoforms after contextual fear memory retrieval may be related to the hippocampal-dependent memory processes of reconsolidation and extinction associated with short and prolonged conditioned context exposure, respectively $[63,89,90]$. These findings encourage the study of the contribution of Homerla and Ania-3 to post retrieval plasticity mechanisms, particularly with regard to their roles in distinct hippocampal subregions that may themselves differentially contribute to extinction and reconsolidation [84, 85, 91-93]. This is the first time that evidence for a role of short Homer isoforms in retrieval-related memory processes, including extinction learning, has been presented. It also implicates Homer1 in specific cognitive processes relevant to psychiatric disorders [33].

\section{Conclusions}

In conclusion, the present results build on previous studies showing that short, activity-induced Homer1 immediate early genes are involved in learning and memory. We present novel findings showing that these short Homer1 variants are expressed not only following the consolidation of contextual fear memories but also accompanying their retrieval and extinction. We also demonstrate for the first time that Homerla and Ania-3 are differentially regulated both temporally and spatially in the hippocampus during fear learning processes and therefore may have different roles in the regulation of long-term contextual fearmemory associations.

\section{Conflicts of Interest}

The authors declare that there is no conflict of interest regarding the publication of this article.

\section{Acknowledgments}

This work was supported by The Waterloo Foundation "Changing Minds" programme, a Wellcome Trust strategic award (100202/Z/12/Z), and a Wellcome Trust PhD studentship to Nicholas E. Clifton.

\section{References}

[1] P. R. Brakeman, A. A. Lanahan, R. O’Brien et al., "Homer: a protein that selectively binds metabotropic glutamate receptors," Nature, vol. 386, no. 6622, pp. 284-288, 1997.

[2] J.-H. Hu, J. M. Park, S. Park et al., "Homeostatic scaling requires group I mGluR activation mediated by Homer1a," Neuron, vol. 68, no. 6, pp. 1128-1142, 2010.

[3] D. Okada, F. Ozawa, and K. Inokuchi, "Input-specific spine entry of soma-derived Vesl-1S protein conforms to synaptic tagging," Science, vol. 324, no. 5929, pp. 904909, 2009.

[4] P. J. Kammermeier, B. Xiao, J. C. Tu, P. F. Worley, and S. R. Ikeda, "Homer proteins regulate coupling of group I metabotropic glutamate receptors to $\mathrm{N}$-type calcium and M-type potassium channels," The Journal of Neuroscience, vol. 20, no. 19, pp. 7238-7245, 2000.

[5] K. D. Lominac, E. B. Oleson, M. Pava et al., "Distinct roles for different Homer1 isoforms in behaviors and associated prefrontal cortex function," The Journal of Neuroscience, vol. 25, no. 50, pp. 11586-11594, 2005. 
[6] M. Klugmann, C. W. Symes, C. B. Leichtlein et al., "AAVmediated hippocampal expression of short and long Homer 1 proteins differentially affect cognition and seizure activity in adult rats," Molecular and Cellular Neurosciences, vol. 28, no. 2, pp. 347-360, 2005.

[7] A. L. Mahan, L. Mou, N. Shah, J.-H. Hu, P. F. Worley, and K. J. Ressler, "Epigenetic modulation of Homerla transcription regulation in amygdala and hippocampus with Pavlovian fear conditioning," The Journal of Neuroscience, vol. 32, no. 13, pp. 4651-4659, 2012.

[8] L. Fagni, P. F. Worley, and F. Ango, "Homer as both a scaffold and transduction molecule," Science Signaling, vol. 2002, no. 137, re8 pages, 2002.

[9] Y. Shiraishi-Yamaguchi and T. Furuichi, "The Homer family proteins," Genome Biology, vol. 8, no. 2, p. 206, 2007.

[10] M. K. Hayashi, C. Tang, C. Verpelli et al., "The postsynaptic density proteins Homer and Shank form a polymeric network structure," Cell, vol. 137, no. 1, pp. 159-171, 2009.

[11] B. Xiao, J. C. Tu, R. S. Petralia et al., "Homer regulates the association of group 1 metabotropic glutamate receptors with multivalent complexes of Homer-related, synaptic proteins," Neuron, vol. 21, no. 4, pp. 707-716, 1998.

[12] P. J. Kammermeier and P. F. Worley, "Homer 1a uncouples metabotropic glutamate receptor 5 from postsynaptic effectors," Proceedings of the National Academy of Sciences of the United States of America, vol. 104, no. 14, pp. 60556060, 2007.

[13] J. C. Tu, B. Xiao, S. Naisbitt et al., "Coupling of mGluR/Homer and PSD-95 complexes by the Shank family of postsynaptic density proteins," Neuron, vol. 23, no. 3, pp. 583-592, 1999.

[14] S. Sylantyev, L. P. Savtchenko, Y. Ermolyuk, P. Michaluk, and D. A. Rusakov, "Spike-driven glutamate electrodiffusion triggers synaptic potentiation via a Homer-dependent mGluR-NMDAR link," Neuron, vol. 77, no. 3, pp. 528-541, 2013.

[15] F. Bertaso, G. Roussignol, P. Worley, J. Bockaert, L. Fagni, and F. Ango, "Homerla-dependent crosstalk between NMDA and metabotropic glutamate receptors in mouse neurons," PLoS One, vol. 5, no. 3, article e9755, 2010.

[16] G. Huang, J. Y. Kim, M. Dehoff et al., " $\mathrm{Ca}^{2+}$ signaling in microdomains: Homerl mediates the interaction between RyR2 and Cav1.2 to regulate excitation-contraction coupling," Journal of Biological Chemistry, vol. 282, no. 19, pp. 1428314290, 2007.

[17] J. P. Yuan, K. P. Lee, J. H. Hong, and S. Muallem, "The closing and opening of TRPC channels by Homer1 and STIM1," Acta Physiologica, vol. 204, no. 2, pp. 238-247, 2012.

[18] J. Y. Kim, W. Zeng, K. Kiselyov et al., "Homer 1 mediates store- and inositol 1,4,5-trisphosphate receptor-dependent translocation and retrieval of TRPC3 to the plasma membrane," Journal of Biological Chemistry, vol. 281, no. 43, pp. 32540-32549, 2006.

[19] P. F. Worley, W. Zeng, G. Huang et al., "Homer proteins in $\mathrm{Ca}^{2+}$ signaling by excitable and non-excitable cells," Cell Calcium, vol. 42, no. 4-5, pp. 363-371, 2007.

[20] C. Sala, K. Futai, K. Yamamoto, P. F. Worley, Y. Hayashi, and M. Sheng, "Inhibition of dendritic spine morphogenesis and synaptic transmission by activity-inducible protein Homerla," The Journal of Neuroscience, vol. 23, no. 15, pp. 6327-6337, 2003.
[21] A. Rozov, A. R. Zivkovic, and M. K. Schwarz, "Homer1 gene products orchestrate $\mathrm{Ca}^{2+}$-permeable AMPA receptor distribution and LTP expression," Frontiers in Synaptic Neuroscience, vol. 4, p. 4, 2012.

[22] S. Hennou, A. Kato, E. M. Schneider et al., "Homer-1a/ Vesl-1S enhances hippocampal synaptic transmission," European Journal of Neuroscience, vol. 18, no. 4, pp. 811819, 2003.

[23] T. Celikel, V. Marx, F. Freudenberg et al., "Select overexpression of Homerla in dorsal hippocampus impairs spatial working memory," Frontiers in Neuroscience, vol. 1, no. 1, pp. 97-110, 2007.

[24] K. Van Keuren-Jensen and H. T. Cline, "Visual experience regulates metabotropic glutamate receptor-mediated plasticity of AMPA receptor synaptic transmission by Homerla induction," The Journal of Neuroscience, vol. 26, no. 29, pp. 7575-7580, 2006.

[25] N. W. Gray, L. Fourgeaud, B. Huang et al., "Dynamin 3 is a component of the postsynapse, where it interacts with mGluR5 and Homer," Current Biology, vol. 13, no. 6, pp. 510-515, 2003.

[26] N. Inoue, H. Nakao, R. Migishima et al., "Requirement of the immediate early gene Vesl-1S/Homer-1a for fear memory formation," Molecular Brain, vol. 2, p. 7, 2009.

[27] G. Kirov, A. J. Pocklington, P. Holmans et al., "De novo CNV analysis implicates specific abnormalities of postsynaptic signalling complexes in the pathogenesis of schizophrenia," Molecular Psychiatry, vol. 17, no. 2, pp. 142-153, 2012.

[28] M. Fromer, A. J. Pocklington, D. H. Kavanagh et al., "De novo mutations in schizophrenia implicate synaptic networks," Nature, vol. 506, no. 7487, pp. 179-184, 2014.

[29] J. Hall, S. Trent, K. L. Thomas, M. C. O’Donovan, and M. J. Owen, "Genetic risk for schizophrenia: convergence on synaptic pathways involved in plasticity," Biological Psychiatry, vol. 77, no. 1, pp. 52-58, 2014.

[30] A. J. Pocklington, M. O’Donovan, and M. J. Owen, “The synapse in schizophrenia," European Journal of Neuroscience, vol. 39, no. 7, pp. 1059-1067, 2014.

[31] S. G. N. Grant, "Synaptopathies: diseases of the synaptome," Current Opinion in Neurobiology, vol. 22, no. 3, pp. 522-529, 2012.

[32] A. J. Pocklington, E. Rees, J. T. R. Walters et al., "Novel findings from CNVs implicate inhibitory and excitatory signaling complexes in schizophrenia," Neuron, vol. 86, no. 5, pp. 1203-1214, 2015.

[33] N. E. Clifton, A. J. Pocklington, B. Scholz et al., "Schizophrenia copy number variants and associative learning," Molecular Psychiatry, vol. 22, pp. 178-182, 2017.

[34] O. Engmann, T. Hortobagyi, R. Pidsley et al., "Schizophrenia is associated with dysregulation of a Cdk5 activator that regulates synaptic protein expression and cognition," Brain, vol. 134, no. 8, pp. 2408-2421, 2011.

[35] S. H. Fatemi, T. D. Folsom, R. E. Kneeland, M. K. Yousefi, S. B. Liesch, and P. D. Thuras, "Impairment of fragile $\mathrm{X}$ mental retardation protein-metabotropic glutamate receptor 5 signaling and its downstream cognates ras-related C3 botulinum toxin substrate 1, amyloid beta A4 precursor protein, striatal-enriched protein tyrosine phosphatase, and Homer 1, in autism: a postmortem study in cerebellar vermis and superior frontal cortex," Molecular Autism, vol. 4, no. 1, p. 21, 2013. 
[36] N. Matosin, F. Fernandez-Enright, J. S. Lum et al., "Molecular evidence of synaptic pathology in the CA1 region in schizophrenia," npj Schizophrenia, vol. 2, article 16022, p. 1, 2016.

[37] K. K. Szumlinski and T. E. Kippin, Homer: A Genetic Factor in Schizophrenia?, P. O. MD, Ed., Cortical Deficits in Schizophrenia: From Genes to Function, Springer US, 2008.

[38] A. De Bartolomeis, C. Sarappa, E. F. Buonaguro et al., "Different effects of the NMDA receptor antagonists ketamine, MK801 , and memantine on postsynaptic density transcripts and their topography: role of Homer signaling, and implications for novel antipsychotic and pro-cognitive targets in psychosis," Progress in Neuro-Psychopharmacology and Biological Psychiatry, vol. 46, pp. 1-12, 2013.

[39] F. Iasevoli, D. Polese, A. Ambesi-Impiombato, G. Muscettola, and A. de Bartolomeis, "Ketamine-related expression of glutamatergic postsynaptic density genes: possible implications in psychosis," Neuroscience Letters, vol. 416, no. 1, pp. 1-5, 2007.

[40] G.-C. Zhang, L.-M. Mao, X.-Y. Liu et al., "In vivo regulation of Homerla expression in the striatum by cocaine," Molecular Pharmacology, vol. 71, no. 4, pp. 1148-1158, 2007.

[41] M. B. Ghasemzadeh, L. K. Windham, R. W. Lake, C. J. Acker, and P. W. Kalivas, "Cocaine activates Homer1 immediate early gene transcription in the mesocorticolimbic circuit: differential regulation by dopamine and glutamate signaling," Synapse, vol. 63, no. 1, pp. 42-53, 2009.

[42] S. Ripke, B. M. Neale, A. Corvin et al., "Biological insights from 108 schizophrenia-associated genetic loci," Nature, vol. 511, pp. 421-427, 2014.

[43] J. A. Ronesi, K. A. Collins, S. A. Hays et al., "Disrupted Homer scaffolds mediate abnormal mGluR5 function in a mouse model of fragile X syndrome," Nature Neuroscience, vol. 15, no. 3, pp. 431-440, 2012.

[44] S. DeRubeis, E. Pasciuto, K. Li et al., "CYFIP1 coordinates mRNA translation and cytoskeleton remodeling to ensure proper dendritic spine formation," Neuron, vol. 79, no. 6, pp. 1169-1182, 2013.

[45] H. Stefansson, D. Rujescu, S. Cichon et al., "Large recurrent microdeletions associated with schizophrenia," Nature, vol. 455, no. 7210, pp. 232-236, 2008.

[46] A. Vazdarjanova, B. L. McNaughton, C. A. Barnes, P. F. Worley, and J. F. Guzowski, "Experience-dependent coincident expression of the effector immediate-early genes Arc and Homer 1a in hippocampal and neocortical neuronal networks," The Journal of Neuroscience, vol. 22, no. 23, pp. 10067-10071, 2002.

[47] S. Peykov, S. Berkel, M. Schoen et al., "Identification and functional characterization of rare SHANK2 variants in schizophrenia," Molecular Psychiatry, vol. 20, no. 12, pp. 1489$1498,2015$.

[48] C. M. Durand, C. Betancur, T. M. Boeckers et al., "Mutations in the gene encoding the synaptic scaffolding protein SHANK3 are associated with autism spectrum disorders," Nature Genetics, vol. 39, no. 1, pp. 25-27, 2007.

[49] N. Norton, H. J. Williams, N. M. Williams et al., "Mutation screening of the Homer gene family and association analysis in schizophrenia," American Journal of Medical Genetics Part B: Neuropsychiatric Genetics, vol. 120B, no. 1, pp. 18-21, 2003.
[50] I. Spellmann, D. Rujescu, R. Musil et al., "Homer-1 polymorphisms are associated with psychopathology and response to treatment in schizophrenic patients," Journal of Psychiatric Research, vol. 45, no. 2, pp. 234-241, 2011.

[51] R. J. Kelleher, U. Geigenmüller, H. Hovhannisyan et al., "Highthroughput sequencing of mGluR signaling pathway genes reveals enrichment of rare variants in autism," PLoS One, vol. 7, no. 4, pp. 11-14, 2012.

[52] M. Rietschel, M. Mattheisen, J. Frank et al., "Genome-wide association-, replication-, and neuroimaging study implicates HOMER1 in the etiology of major depression," Biological Psychiatry, vol. 68, no. 6, pp. 578-585, 2010.

[53] J. Strauss, S. McGregor, N. Freeman et al., "Association study of early-immediate genes in childhood-onset mood disorders and suicide attempt," Psychiatry Research, vol. 197, no. 1-2, pp. 49-54, 2012.

[54] C. D. Nichols, E. E. Garcia, and E. Sanders-Bush, "Dynamic changes in prefrontal cortex gene expression following lysergic acid diethylamide administration," Molecular Brain Research, vol. 111, no. 1-2, pp. 182-188, 2003.

[55] L. M. Igaz, P. Bekinschtein, I. Izquierdo, and J. H. Medina, "One-trial aversive learning induces late changes in hippocampal CaMKII $\alpha$, Homer 1a, Syntaxin 1a and ERK2 protein levels," Molecular Brain Research, vol. 132, no. 1, pp. 1-12, 2004.

[56] A. W. Ary, V. R. Aguilar, K. K. Szumlinski, and T. E. Kippin, "Prenatal stress alters limbo-corticostriatal Homer protein expression," Synapse, vol. 61, no. 11, pp. 938-941, 2007.

[57] P. J. Hernandez, C. A. Schiltz, and A. E. Kelley, "Dynamic shifts in corticostriatal expression patterns of the immediate early genes Homer 1a and Zif268 during early and late phases of instrumental training," Learning \& Memory, vol. 13, no. 5, pp. 599-608, 2006.

[58] M. R. Milad and G. J. Quirk, "Fear extinction as a model for translational neuroscience: ten years of progress," Annual Review of Psychology, vol. 63, no. 1, pp. 129-151, 2012.

[59] S. Maren, K. L. Phan, and I. Liberzon, "The contextual brain: implications for fear conditioning, extinction and psychopathology," Nature Reviews Neuroscience, vol. 14, pp. 417-428, 2013.

[60] M. S. Fanselow, "Factors governing one-trial contextual conditioning," Animal Learning \& Behavior, vol. 18, no. 3, pp. 264270, 1990.

[61] J. W. Rudy, "Context representations, context functions, and the parahippocampal-hippocampal system," Learning \& Memory, vol. 16, no. 10, pp. 573-585, 2009.

[62] A. Asok, W. B. Schreiber, S. A. Jablonski, J. B. Rosen, and M. E. Stanton, "Egr-1 increases in the prefrontal cortex following training in the context preexposure facilitation effect (CPFE) paradigm," Neurobiology of Learning and Memory, vol. 106, pp. 145-153, 2013.

[63] J. L. C. Lee, B. J. Everitt, and K. L. Thomas, "Independent cellular processes for hippocampal memory consolidation and reconsolidation," Science, vol. 304, no. 5672, pp. 839-843, 2004.

[64] P. Barnes and K. L. Thomas, "Proteolysis of proBDNF is a key regulator in the formation of memory," PLoS One, vol. 3, no. 9, article e3248, 2008.

[65] A. Kirtley and K. L. Thomas, "The exclusive induction of extinction is gated by BDNF," Learning \& Memory, vol. 17, no. 12 , pp. $612-619,2010$. 
[66] F. Iasevoli, C. Tomasetti, F. Marmo, D. Bravi, J. Arnt, and A. De Bartolomeis, "Divergent acute and chronic modulation of glutamatergic postsynaptic density genes expression by the antipsychotics haloperidol and sertindole," Psychopharmacology, vol. 212, no. 3, pp. 329-344, 2010.

[67] G. L. Lyford, K. Yamagata, W. E. Kaufmann et al., “Arc, a growth factor and activity-regulated gene, encodes a novel cytoskeleton-associated protein that is enriched in neuronal dendrites," Neuron, vol. 14, no. 2, pp. 433-445, 1995.

[68] E. Shimizu, Y. P. Tang, C. Rampon, and J. Z. Tsien, "NMDA receptor-dependent synaptic reinforcement as a crucial process for memory consolidation," Science, vol. 290, no. 5494, pp. 1170-1174, 2000.

[69] S. Daumas, H. Halley, B. Francés, and J. M. Lassalle, "Encoding, consolidation, and retrieval of contextual memory: differential involvement of dorsal CA3 and CA1 hippocampal subregions," Learning \& Memory, vol. 12, no. 4, pp. 375-382, 2005.

[70] K. I. Blum and L. F. Abbott, "A model of spatial map formation in the hippocampus of the rat," Neural Computation, vol. 8, no. 1, pp. 85-93, 1996.

[71] R. C. Honey and M. Good, "Associative modulation of the orienting response: distinct effects revealed by hippocampal lesions," Journal of Experimental Psychology Animal Behavior Processes, vol. 26, no. 1, pp. 3-14, 2000.

[72] O. S. Vinogradova, "Hippocampus as comparator: role of the two input and two output systems of the hippocampus in selection and registration of information," Hippocampus, vol. 11, no. 5, pp. 578-598, 2001.

[73] D. Kumaran and E. A. Maguire, "Which computational mechanisms operate in the hippocampus during novelty detection?," Hippocampus, vol. 17, no. 9, pp. 735-748, 2007.

[74] E. J. Barbeau, P. Chauvel, C. J. A. Moulin, J. Regis, and C. Liégeois-Chauvel, "Hippocampus duality: memory and novelty detection are subserved by distinct mechanisms," Hippocampus, vol. 27, no. 4, pp. 405-416, 2017.

[75] M. E. Hasselmo and B. P. Wyble, "Free recall and recognition in a network model of the hippocampus: simulating effects of scopolamine on human memory function," Behavioural Brain Research, vol. 89, no. 1-2, pp. 1-34, 1997.

[76] P. E. Gilbert and R. P. Kesner, "Localization of function within the dorsal hippocampus: the role of the CA3 subregion in paired-associate learning," Behavioral Neuroscience, vol. 117, no. 6, pp. 1385-1394, 2003.

[77] R. P. Kesner, M. R. Hunsaker, and M. W. Warthen, "The CA3 subregion of the hippocampus is critical for episodic memory processing by means of relational encoding in rats," Behavioral Neuroscience, vol. 122, no. 6, pp. 1217-1225, 2008.

[78] T. Rajji, D. Chapman, H. Eichenbaum, and R. Greene, “The role of CA3 hippocampal NMDA receptors in paired associate learning," The Journal of Neuroscience, vol. 26, no. 3, pp. 908915, 2006.

[79] R. W. Komorowski, J. R. Manns, and H. Eichenbaum, "Robust conjunctive item-place coding by hippocampal neurons parallels learning what happens where," The Journal of Neuroscience, vol. 29, no. 31, pp. 9918-9929, 2009.

[80] R. P. Kesner, "Behavioral functions of the CA3 subregion of the hippocampus," Learning \& Memory, vol. 14, no. 11, pp. 771-781, 2007.

[81] A. M. Morris, C. S. Weeden, J. C. Churchwell, and R. P. Kesner, "The role of the dentate gyrus in the formation of contextual representations," Hippocampus, vol. 23, no. 2, pp. 162-168, 2012.

[82] I. Lee and R. P. Kesner, "Encoding versus retrieval of spatial memory: double dissociation between the dentate gyrus and the perforant path inputs into CA3 in the dorsal hippocampus," Hippocampus, vol. 14, no. 1, pp. 66-76, 2004.

[83] N. J. Goodrich-Hunsaker, M. R. Hunsaker, and R. P. Kesner, "The interactions and dissociations of the dorsal hippocampus subregions: how the dentate gyrus, CA3, and CA1 process spatial information," Behavioral Neuroscience, vol. 122, no. 1, pp. 16-26, 2008.

[84] J. Ji and S. Maren, "Differential roles for hippocampal areas CA1 and CA3 in the contextual encoding and retrieval of extinguished fear," Learning \& Memory, vol. 15, no. 4, pp. 244-251, 2008.

[85] B. E. Bernier, A. F. Lacagnina, A. Ayoub et al., "Dentate gyrus contributes to retrieval as well as encoding: evidence from context fear conditioning, recall, and extinction," The Journal of Neuroscience, vol. 10, pp. 3029-3016, 2017.

[86] J. F. Guzowski, T. Miyashita, M. K. Chawla et al., "Recent behavioral history modifies coupling between cell activity and Arc gene transcription in hippocampal CA1 neurons," Proceedings of the National Academy of Sciences of the United States of America, vol. 103, no. 4, pp. 1077-1082, 2006.

[87] N. Mamiya, H. Fukushima, A. Suzuki et al., "Brain regionspecific gene expression activation required for reconsolidation and extinction of contextual fear memory," Journal of Neuroscience, vol. 29, no. 2, pp. 402-413, 2009.

[88] B. Antoine, L. Serge, and C. Jocelyne, "Comparative dynamics of MAPK/ERK signalling components and immediate early genes in the hippocampus and amygdala following contextual fear conditioning and retrieval," Brain Structure and Function, vol. 219, no. 1, pp. 415-430, 2014.

[89] A. Suzuki, S. A. Josselyn, P. W. Frankland, S. Masushige, A. J. Silva, and S. Kida, "Memory reconsolidation and extinction have distinct temporal and biochemical signatures," The Journal of Neuroscience, vol. 24, no. 20, pp. 4787-4795, 2004.

[90] S. Trent, P. Barnes, J. Hall, and K. L. Thomas, "Rescue of longterm memory after reconsolidation blockade," Nature Communications, vol. 6, p. 7897, 2015.

[91] J. Artinian, X. De Jaeger, L. Fellini, P. De Saint Blanquat, and P. Roullet, "Reactivation with a simple exposure to the experimental environment is sufficient to induce reconsolidation requiring protein synthesis in the hippocampal CA3 region in mice," Hippocampus, vol. 17, no. 3, pp. 181-191, 2007.

[92] S. J. Hirsch, N. L. Regmi, S. G. Birnbaum, and R. W. Greene, "CA1-specific deletion of NMDA receptors induces abnormal renewal of a learned fear response," Hippocampus, vol. 25, no. 11, pp. 1374-1379, 2015.

[93] V. Lux, O. A. Masseck, S. Herlitze, and M. M. Sauvage, "Optogenetic destabilization of the memory trace in CA1: insights into reconsolidation and retrieval processes," Cerebral Cortex, vol. 27, no. 1, pp. 841-851, 2015. 

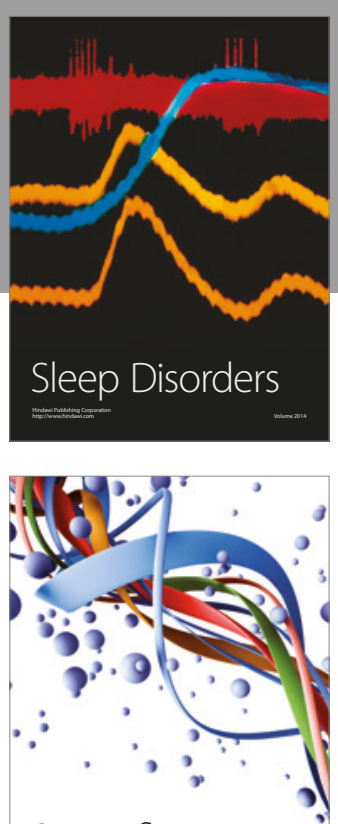

Scientifica
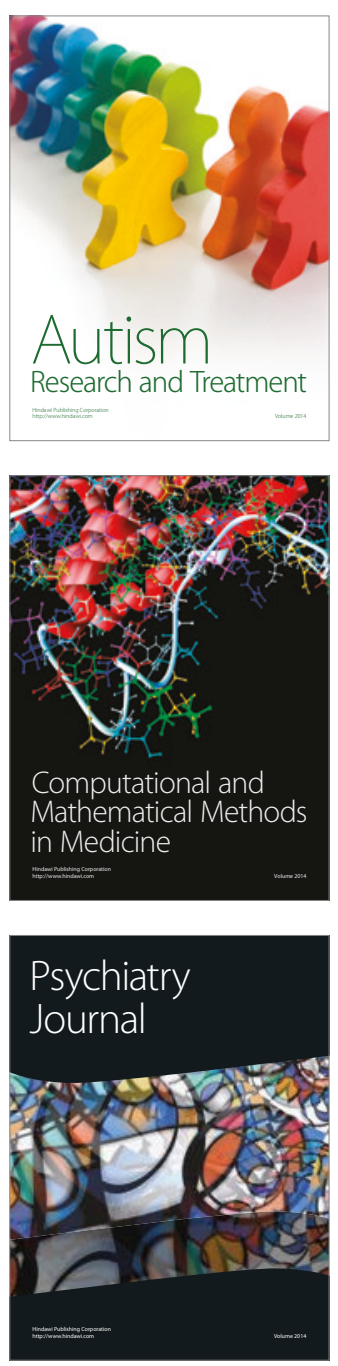
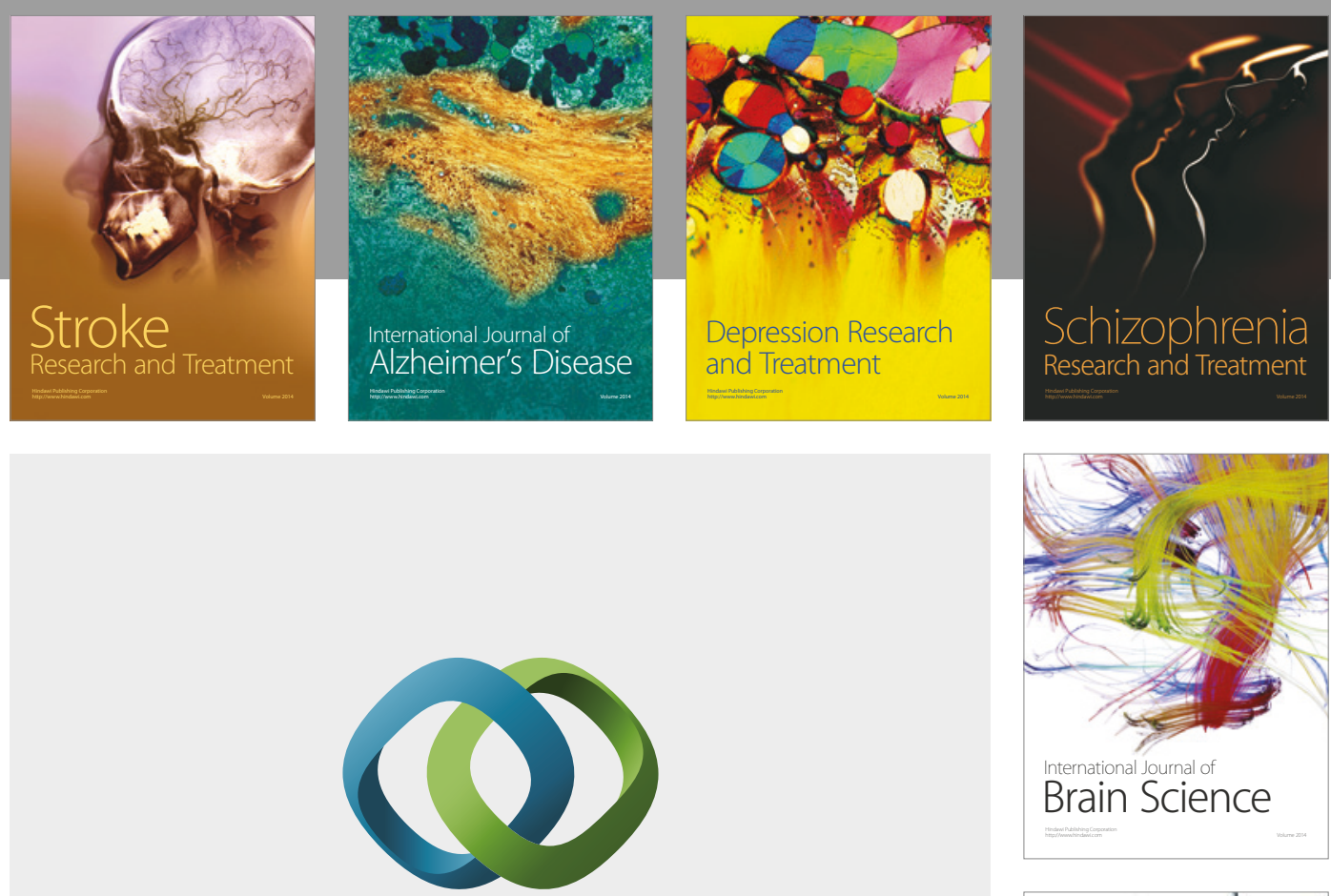

\section{Hindawi}

Submit your manuscripts at

https://www.hindawi.com
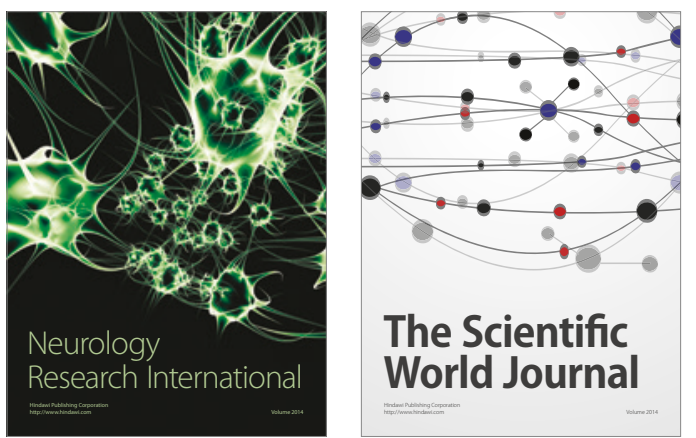

The Scientific World Journal

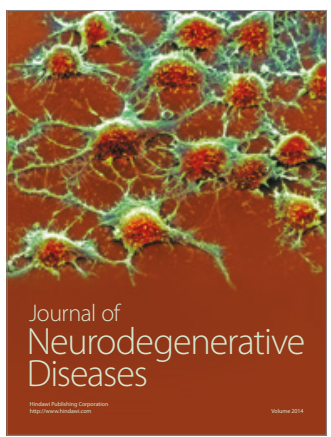

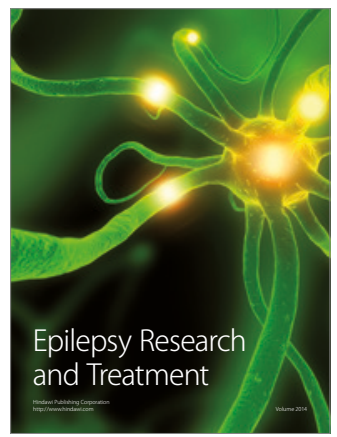

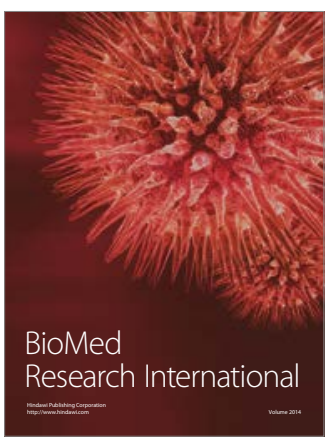

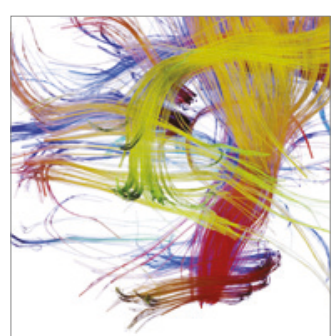

Brain Science

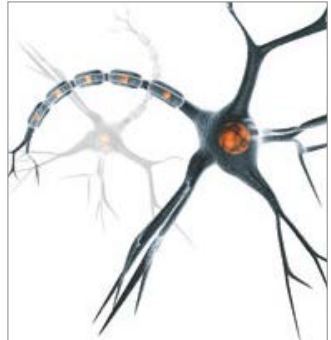

Neural Plasticity
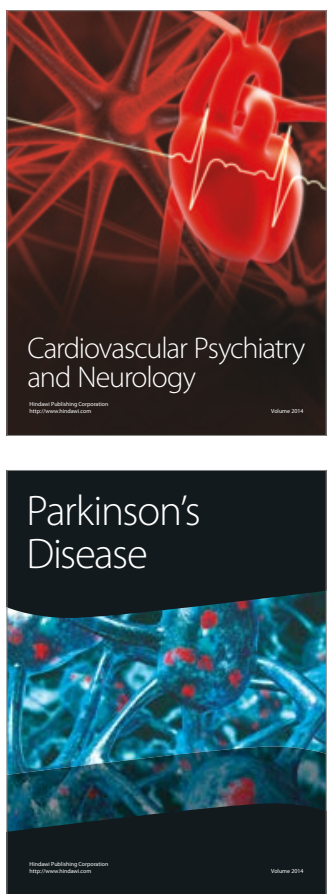